\title{
Optimal Control of Model Reduction Binary Distillation Column
}

\author{
Nasir Ahmed Alawad \\ Department of Computer Engineering, Faculty of Engineering, Mustansiriyah University, Baghdad, IRAQ \\ E-mail: nasir.awad@uomustansiriyah.edu.iq \\ Afaf Jebar Muter \\ Department of Computer Engineering, Faculty of Engineering, Mustansiriyah University, Baghdad, IRAQ \\ E-mail: afak.jeber@gmail.com
}

Received: 01 April 2020; Accepted: 08 May 2020; Published: 08 February 2021

\begin{abstract}
A binary distillation process with desired composition rate is considered. The aim is to find a control (Top and bottom compositions) which is optimal with respect to energy consumption and which is robust at the same time with respect to the response speed(less time) and minimum overshot. The solution approach is based on the formulation of two optimization techniques, Invasive Wood (IWO) and Differential Evolution (DE) with respect to Integral Square Error (ISE) and Integral Absolute Error (IAE) fitness function with using Proportinal_Integral-Derivative (PID) controller. An overall model including the dynamics of the distillation process is assumed with model reduction methods. This optimal control is compared with classical approach. The numerical results are presented and showed the effectiveness of the proposed control. MATLAB package is used for simulation and analysis.
\end{abstract}

Index Terms: Optimal control, Distillation column, Model Reduction, PID controller

\section{Introduction}

The distillation column is an essential unit operation used notably in chemical industries to separate solutions of compounds into individual elements primarily based on their one of a kind boiling point. With its large number of equations, this system can be viewed as large-scale chemical plant whose modeling and manipulate has been an interesting problem of study [1,2]. Optimal control problems, where the desired state is to be reached in minimum time, are important in the operation of engineering systems for example, in the distillation column, we may wish to reach the desired state of operation as fast as possible and with more stability [3].

Many optimization-based controllers have been proposed by researchers. model predictive control(MPC) are adopted for control of distillation columns since they allow to synthesize optimal control actions while simultaneously respecting constraints on manipulated variables and controlled outputs[4].

Nowadays, many centralized optimization algorithms, such as variation calculus-based methods, nonlinear programming and dynamic programming have been proposed for solving optimal control problems[5,6].[7] have studied the energy efficiency optimization for distillation column using artificial neural network models and showed that by having an accurate model the energy efficiency could be improved. In[8], an adaptive generalized predictive controller is designed to achieve the optimal operating conditions for controlling the packed distillation column for regulatory problems.[9] presents the design PID) controller, using the Biggest Log Modulus Tuning (BLT) in state space and calculating the controller as the Biggest Log Modulus Tuning algorithm.

[10] is presented a decentralized control scheme to achieve optimal and economic performance using controlling both pressure and temperature.[11]is presented an intelligent predictive controller, where a neural network predicts the behavior of the system and a genetic algorithm modifies the controller's parameters based on an optimization problem.

The optimal manage problem studied in this paper is to carry the binary distillation response to minimal time, with less overshoot and satisfied the desired compositions at two sides of column (top and bottom).

There are many researchers are dealing with the optimization of distillation column.[12] showed that selfoptimizing control is a strategy for selecting controlled variables, but still the complex for a selection criterion to do it.[13] showed that for acceptable controller design, The accurate design of distillation columns is a very important, so that the model reduction plays an additional factor.[14] showed that using a tuning rule focusing on a genetic algorithm to determine the optimal PI/PID control settings for binary distillation column model to give easier procedure when compared with traditional optimization techniques. This problem, which can also be optimized by minimization 
of an (ISE) and (IAE) performances index, which area well known problem considered by many researchers. In this paper utilizes the soft-computing techniques (IWO) and (DE) which are more used for designing multivariable control systems to obtain the best optimal control, when compared with classical control methods.

The remainder of the paper is organized as follows: Section II presents the dynamic model of the distillation column. Section III presents model reduction of distillation column. Section IV explains the controller's types for distillation process, classical and optimal. Section V presents the results and discussion, with a comparison between the controllers based on simulation results. Finally, Section VI contains the main conclusions.

\section{Distillation Column Model}

The process considered relates to a distillation column, as shown in Figure 1, for separating a binary mixture of water and methanol. Wood and Berry is more practical column used until now for many studies and control $[12,13.14,15]$.

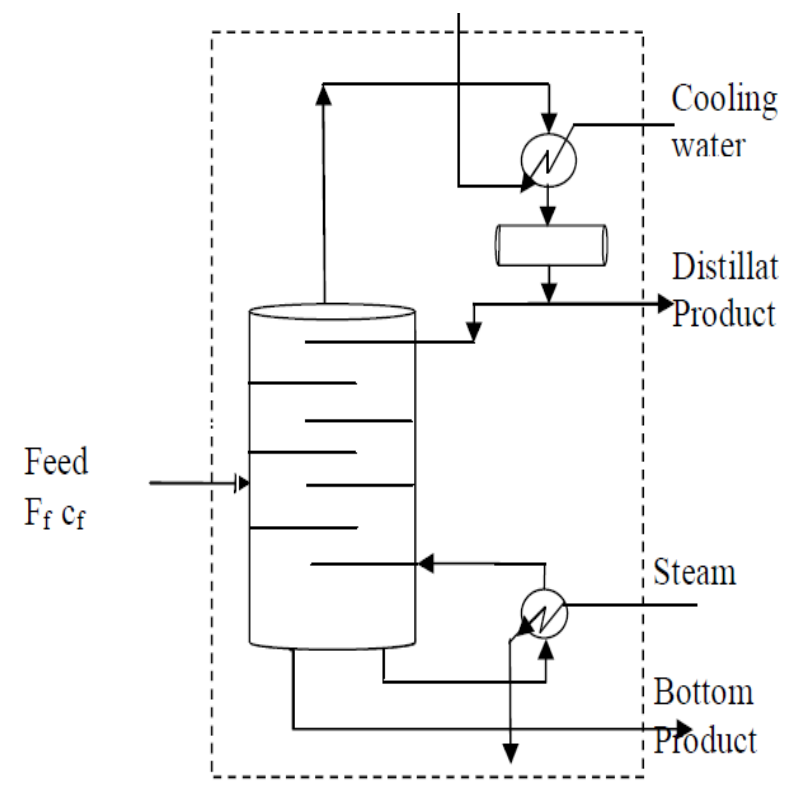

Fig.1. Schematic diagram of binary distillation column

The model consists of 8 plates, plus a condenser and a reboiler. The control is achieved by changing the heat input to the reboiler and the heat withdrawn from the condenser. There are two control variables (XD for top)and(XB for bottom) and two manipulated variables(Reflux rate L)and(steam rate V).Generally ,the matrix system is[16]:-

$$
\left[\begin{array}{l}
x_{D} \\
x_{B}
\end{array}\right]=G(s)\left[\begin{array}{l}
L(s) \\
V(s)
\end{array}\right]
$$

Where $G(s)=\left[\begin{array}{lll}G_{11} & (s) & G_{12}(s) \\ G_{21} & (s) & G_{22}(s)\end{array}\right]$ is the system matrix

For Wood and Berry is:-

$$
G(s)=\left[\begin{array}{cc}
\frac{12.8 e^{-s}}{16.7 s+1} & \frac{-18.9 e^{-s}}{21 s+1} \\
\frac{6.6 e^{-7 s}}{10.9 s+1} & \frac{-19.4 e^{-3 s}}{14.4 s+1}
\end{array}\right]
$$

Since the G(s) is multivariable system, so that there are interaction between the loops, where change the input (L) to control (XD), the (XB) also change, in this state, a decoupling is needed to prevent it. There are many decoupling schemes were developed during past 30 years for two-input two-output (TITO) systems and have been wellsummarized in many literature and process control textbooks[17,18,19].In this paper, the simplified decoupler is used, because it is simple and direct calculated ,but the main disadvantage is resulted a big dimension of decoupler matrix. 


\section{A. Simplified Decoupling}

This decoupling control design, called "simplified decoupling" by Luyben [20], is widely used in the literature. It consists in selecting the decoupler as follows:

$$
D(s)=\left[\begin{array}{cc}
1 & \frac{-g_{12}}{g_{11}} \\
\frac{-g_{21}}{g_{22}} & 1
\end{array}\right]
$$

The resulting transfer matrix decoupler $T(s)$ is:-

$$
T(s)=\left[\begin{array}{cc}
g_{11}(s)-\frac{g_{12}(s) g_{21}(s)}{g_{22}(s)} & 0 \\
0 & g_{22}(s)-\frac{g_{12}(s) g_{21}(s)}{g_{11}(s)}
\end{array}\right]
$$

This choice makes the realization of the decoupler easy, but the diagonal transfer matrix $T(s)$ obtained is complex since its elements are the sum of transfer functions. Controller tuning can therefore be difficult. It is then often suggested to approximate each sum by a simpler transfer function to facilitate controller tuning. Taking WB column , equ(2), and using equ(3), the decoupler is:-

$$
D(s)=\left[\begin{array}{cc}
1 & \frac{1.476(16.7 s+1) e^{-2 s}}{16.7 s+1} \\
\frac{0.33(14.2 s+1) e^{-4 s}}{10.89 s+1} & 1
\end{array}\right]
$$

Then, according to equation (4), the diagonal matrix of WB column is given by

$$
\begin{aligned}
& \overline{g_{11}}(\mathrm{~s})=\frac{12.8 e^{-s}}{16.7 s+1}-\frac{6.237(14.36 s+1) e^{-7 s}}{228.69 s^{2}+31.89 s+1} \\
& \overline{g_{22}}(\mathrm{~s})=\frac{-19.4 e^{-3 s}}{14.4 s+1}+\frac{9.745(16.7 s+1) e^{-9 s}}{228.69 s^{2}+31.89 s+1}
\end{aligned}
$$

To simplify the equations in (6) and (7), pade approximation is used to remove the nonlinear term in equations by using the following equation [21]:-

$$
\mathrm{e}^{-\theta \mathrm{s}} \approx \frac{1-\frac{\theta}{2} s}{1+\frac{\theta}{2} s}
$$

where $(\theta)$ is the delay term. The first term of equation (6) becomes:-

$$
\frac{-12.8 s+25.6}{16.7 s^{2}+34.4 s+2}
$$

And the second term of equation (6) becomes:-

$$
\frac{-89.56 s^{2}+19.35 s+1.782}{228.7 s^{3}+97.23 s^{2}+10.11 s+0.2857}
$$

By the summing the equations (9) and (10) the result is:-

$$
\mathrm{G}_{11 \mathrm{WB}}=\frac{-1432 s^{4}+7368 s^{3}+1843 s^{2}+155.2 s+3.75}{3819 s^{5}+9491 s^{4}+3971 s^{3}+547.1 s^{2}+30.05 s+0.5714}
$$

Also the first term of equation (7) becomes:-

$$
\frac{19.4 s-12.93}{14.4 s^{2}+10.6 s+0.6667}
$$

And the second term of the equation (7) becomes:- 


$$
\frac{162.7 s^{2}+26.42 s+2.166}{228.7 s^{3}+82.71 s^{2}+8.087 s+0.2222}
$$

By the summing the equations (12) and (13) the result is:-

$$
\mathrm{G}_{22 \mathrm{WB}}=\frac{2093 s^{4}-2698 s^{3}-710.1 s^{2}-59.71 s-1.43}{3293 s^{5}+3615 s^{4}+1146 s^{3}+144.1 s^{2}+7.747 s+0.1481}
$$

It is seen that, they obtained equations $(11,14)$ are of high order and these made complex and difficult to design and analysis, so model reduction techniques is used to reduce the order of these equations.

\section{Distillation Column Model Reduction}

In this work, we present a highly-accurate technique of model order reduction applied to distillation column. The proposed method reduces the dimension of the original system based on Evolutionary Algorithm (EA) which is a generic population-based meta-heuristic optimization algorithm. An EA uses some mechanisms inspired by biological evolution: reproduction, mutation, recombination, natural selection and survival of the fittest. In this type of reduction, there are many methods; Genetic Algorithms(GA) and Particle Swarm Optimization(PSO) are two famous Evolutionary Algorithms [22].In this work, (PSO) is used.

\section{PSO}

is a biologically inspired algorithm and it is a population based stochastic nature. Each individual is referred to a particle and can move in the search space in all the directions in such a way that it reaches optimal solution. The steps of PSO algorithm are used [23].MTLAB package to execute, with the following parameters:-

Generation count limit $=200$, population size $=50$, problem dimension $=5$, mutation probability $=0.06$, number of elites $=2$, after exploitation improvement program, the reduced transfer function for applying PSO algorithm to equation (11)is :-

$$
\mathrm{G}_{11 \mathrm{rWB}}=\frac{0.8498 s+0.5051}{s^{2}+0.9989 s+0.077}
$$

The step responses of the reduced order model and the original system are compared; in Fig.2.while table.1 shows the transient specifications comparison between original and reduced systems.

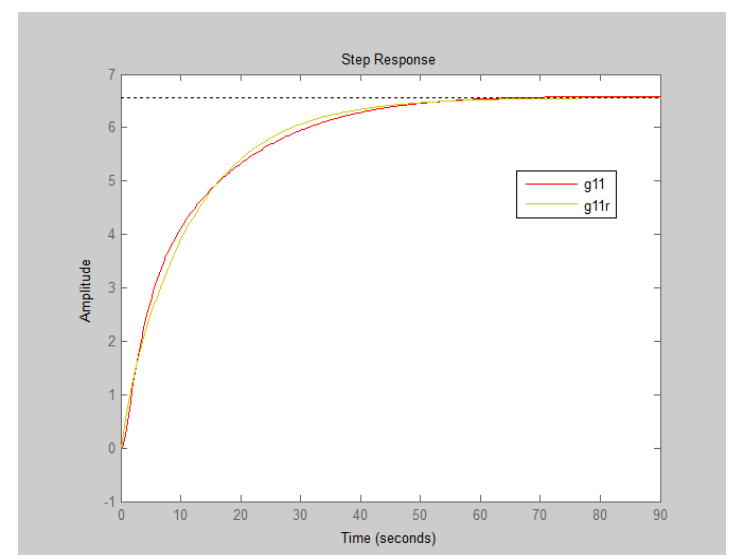

Fig.2. shows step response comparison of original $\mathrm{G}_{11 \mathrm{WB}}$ and reduced order system $\mathrm{G}_{11 \mathrm{rWB}}$

Table.1 Transient specifications comparison

\begin{tabular}{|c|c|c|}
\hline Characteristics & $\mathrm{G}_{11 \mathrm{WB}(\text { original) }}$ & $\mathrm{G}_{11 \mathrm{rWB} \text { (proposed) }}$ \\
\hline $\mathrm{Ts}$ & 48.4 & 45.8 \\
\hline $\mathrm{Tr}$ & 27.5 & 25.8 \\
\hline $\mathrm{Mp}$ & $0.273 \%$ & $0.272 \%$ \\
\hline Ess & 6.43 & 6.43 \\
\hline
\end{tabular}


And for equation (14) is :-

$$
\mathrm{G}_{22 \mathrm{rWB}}=\frac{0.7324 s-1}{0.7811 s^{2}+1.047 s+0.1049}
$$

The step responses of the reduced order model and the original system are compared in Fig.3.For transient specifications, the original and reduced systems are compared as shown in table 2.

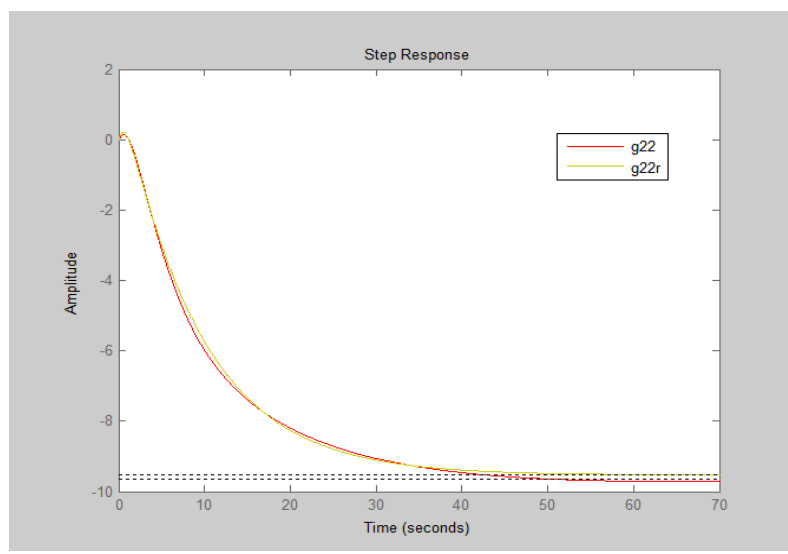

Fig.3. shows step response comparison of original $\mathrm{G}_{22 \mathrm{WB}}$ and reduced order system $\mathrm{G}_{22 \mathrm{rWB}}$

Table.2 Transient specifications comparison

\begin{tabular}{|c|c|c|}
\hline Characteristics & $\mathbf{G}_{\mathbf{2 2} \text { WB(original) }}$ & $\mathbf{G}_{\mathbf{2 2} \mathbf{r W B} \text { (proposed) }}$ \\
\hline $\mathrm{Ts}$ & 40.7 & 37.2 \\
\hline $\mathrm{Tr}$ & 21.5 & 20.2 \\
\hline $\mathrm{Mp}$ & $0.65 \%$ & $0 \%$ \\
\hline Ess & -0.193 & -0.193 \\
\hline
\end{tabular}

As seen from figs(2,3) and tables(1,2), the reduction models by the proposed method of Wb are very close to the original model specially in settling and rise time.

\section{Control Strategies for Distillation Column System}

There are many control strategies applied to distillation column multivariable system[24,25]:-

- Centralized structure

- Decentralized structure

- Decoupled structure

In this paper, Decentralized Decoupling structure control strategy is used, where the proposed algorithm involves combination of simplified decoupler, and decentralized controller with optimal PI design with model reduction of the effective transfer function, for the models under test. Fig(4) shows controlled structure block-diagram.

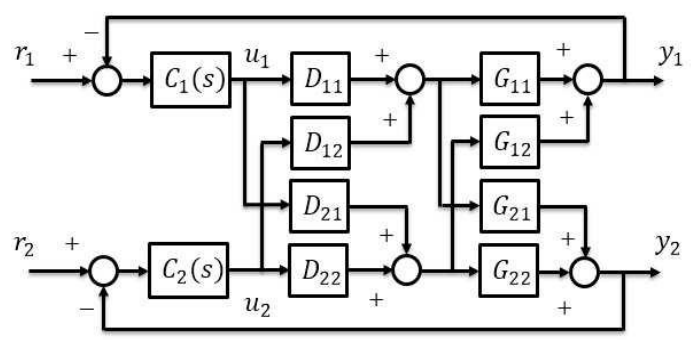

Fig.4 shows controlled structure block-diagram 
For Tuning of Controller (PI) Parameters C1(s) and C2(s) based on Optimization Algorithms, The optimal parameters of the PI (Kp, Ki) can be obtained by applying DE and IWO algorithm. The DE and IWO algorithms are depended on the fitness function (performance index). Generally there are many types of performance index, but in this work using only:-

$$
\begin{gathered}
I S E_{r}=\int_{0}^{\infty} \mathrm{e}^{2}(t) d t \\
I A E=\int_{0}^{\infty}|\mathrm{e}| d t
\end{gathered}
$$

These fitness functions are adopted to find the fitness of each solution in population size for both DE and IWO algorithms.

For design specifications, it is required to reach minimum overshoot(Mp\%), stable system behavior and speedy responses settling time(Ts) and more accuracy system, zero steady-state error.

\section{DE Algorithm}

In [26] is proposed a new floating point encoded evolutionary algorithm for global optimization and named it DE owing to a special kind of differential operator, which they invoked to create new offspring from parent chromosomes instead of classical crossover or mutation. The parameters of the DE determined by trial and error with its specific ranges are listed in Table.3.

Table. 3 The DE algorithm parameters.

\begin{tabular}{|c|c|}
\hline Parameters & Value \\
\hline Problem dimension (D) & 5 \\
\hline Population size (NP) & 25 \\
\hline Crossover constant (CR) & 0.6 \\
\hline Scaling constant (F) & 0.95 \\
\hline Number of generation (GEN) & 20 \\
\hline
\end{tabular}

\section{IWO Algorithm}

(IWO) Optimization algorithm was first introduced in [27]. Weeds invade the fields by dispersing their seeds with the help of air. These seeds occupy the available spaces and grow into flowering weeds by utilizing the available resources. Those weeds that adapt well to the environment produce more seeds than others. These new weeds are dispersed randomly in the field and they grow into flowering weeds and the process continues. This competition among the weeds makes them adapt well to the environment [28]. The parameters of the IWO determined by trial and error with its specific ranges are listed in Table.4.

Table. 4 The IWO algorithm parameters.

\begin{tabular}{|c|c|}
\hline Parameters & Value \\
\hline Number of Generation & 20 \\
\hline Initial Population Size & 2 \\
\hline Maximum Population Size & 10 \\
\hline Minimum Number of Seeds & 0 \\
\hline Maximum Number of Seeds & 5 \\
\hline Initial Value of Standard Deviation & 0.5 \\
\hline Final Value of Standard Deviation & 0.001 \\
\hline
\end{tabular}

\section{Simulation Results and Discussion}

This part demonstrates and discusses the suggested controller's simulation results and this is done using Matlab simulation package.

\section{A. Controlling XD for $G_{11 r W B}$}

It is required to find the optimal values of the PI controller gains ( $\mathrm{Kp}, \mathrm{Ki}$ ) to minimize the ISE and IAE performance indices using DE, IWO. Assume the input $=0.98$ with lower and upper bounders [20 20], [30 30 ] respectively for DE-PI and with lower and upper bounders [0 0 ], [10 10] respectively for IWO-PI. Firstly, using MATLAB tool for the model (wood and berry g11rWB), to find the PI parameters controller, the results are depicted in 
Table.5 and transient response specifications are shows in Table.6 for ISE, while table.7 and table.8 for IAE.Fig.5 and 6 shows step response controlled system for ISE and IAE respectively.

Table.5 The optimal parameters of PI controller for $\mathrm{G}_{11 \mathrm{rWB}}$ using performance index ISE

\begin{tabular}{|c|c|c|c|}
\hline Controller type & $\boldsymbol{K}_{\boldsymbol{P}}$ & $\boldsymbol{K}_{\boldsymbol{i}}$ & $\begin{array}{c}\text { Average No. of } \\
\text { Iteration }\end{array}$ \\
\hline PI-MATLAB & 0.0764 & 0.0242 & \\
\hline DE-PI & 29.9777 & 28.8345 & 15 \\
\hline IWO-PI & 4.8755 & 2.0777 & 15 \\
\hline
\end{tabular}

Table 6 Transient response parameters of $\mathrm{G}_{11 \mathrm{rWB}}$ for ISE

\begin{tabular}{|c|c|c|c|c|}
\hline Controller types & Mp\% & Ts(minute) & $\operatorname{Tr}(\operatorname{minute})$ & Ess \\
\hline Without controller & 0.13 & 3.67 & 7.72 & 0.13 \\
\hline PI-MATLAB & 12.4074 & 46.6524 & 13.8450 & 0 \\
\hline PI-DE(ISE) & 1.2039 & 1.9683 & 0.7905 & 0 \\
\hline PI-IWO(ISE) & 3.1146 & 4.9061 & 0.5105 & 0 \\
\hline
\end{tabular}

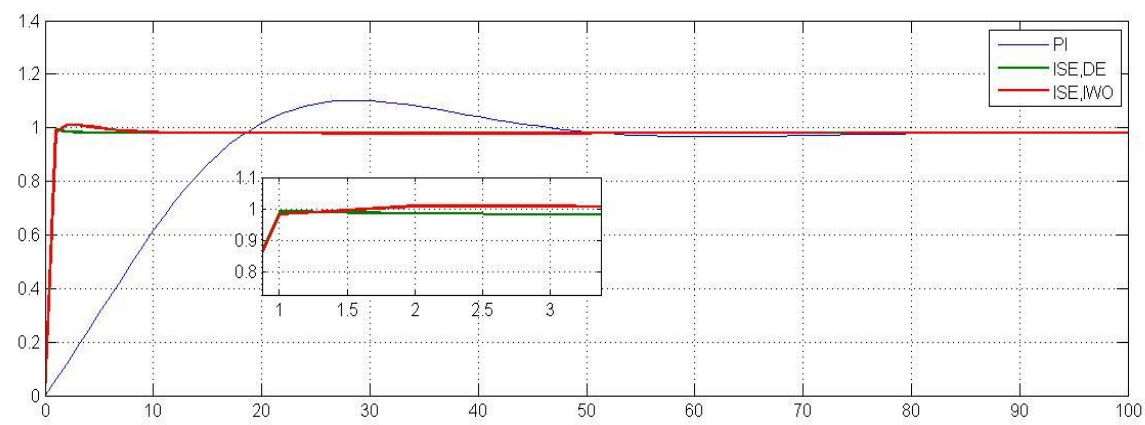

Fig.5 Step Response of PI Controller and PI Controller using DE, IWO for ISE

Table.7 The optimal parameters of PI controller for $\mathrm{G}_{11 \mathrm{rWB}}$ using performance index IAE

\begin{tabular}{|c|c|c|c|}
\hline Controller type & $\boldsymbol{K}_{\boldsymbol{P}}$ & $\boldsymbol{K}_{\boldsymbol{i}}$ & $\begin{array}{c}\text { Average No. of } \\
\text { Iteration }\end{array}$ \\
\hline PI-MATLAB & 0.0764 & 0.0242 & \\
\hline DE-PI & 24.501 & 24.601 & 15 \\
\hline IWO-PI & 5.1002 & 5.0121 & 15 \\
\hline
\end{tabular}

Table. 8 Transient response parameters of $\mathrm{G}_{11 \mathrm{rWB}}$ for IAE

\begin{tabular}{|c|c|c|c|c|}
\hline Controller types & $\mathrm{Mp} \%$ & $\operatorname{Ts}($ minute) & $\operatorname{Tr}(\mathrm{minute})$ & Ess \\
\hline Without controller & 0.13 & 3.67 & 7.72 & 0.13 \\
\hline PI-MATLAB & 12.4074 & 46.6524 & 13.8450 & 0 \\
\hline PI-DE (IAE) & 2.3725 & 0.6299 & 0.0977 & 0 \\
\hline PI-IWO (IAE) & 7.9654 & 3.1801 & 0.3889 & 0 \\
\hline
\end{tabular}

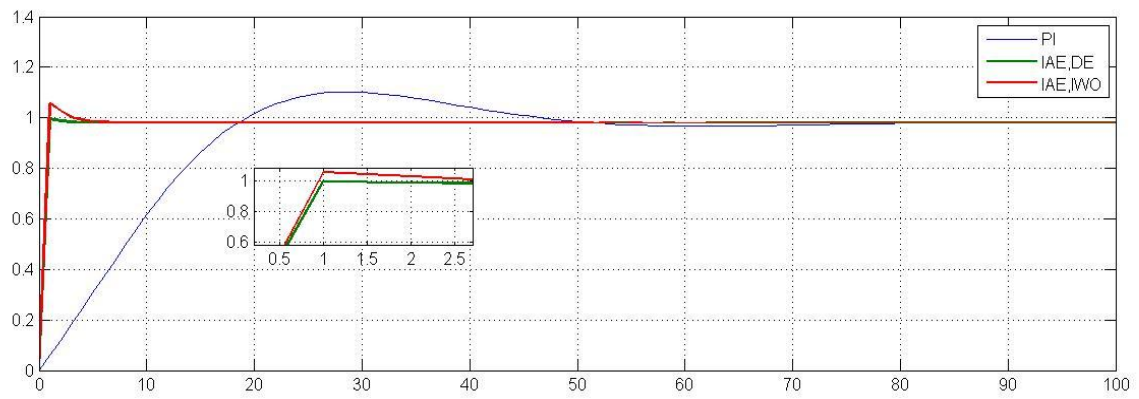

Fig.6. Step Response of PI Controller and PI Controller using DE, IWO for IAE

Figure (5) illustrates the responses of the three controllers when the performance index is ISE. As shown in this figure, the system with MATAB- PI controller gives overshoot $12.4074 \%$, rise time $13.8450 \mathrm{~min}$, and settling time (2\% criterion) $46.6524 \mathrm{~min}$. While the system with PID-DE controller results in less overshoot $1.2039 \%$, less rise time $0.7905 \mathrm{~min}$, and settling time $1.9683 \mathrm{~min}$ and for IWO , give also best result, when compared with the MATLAB-PID, 
but not best than using PID-DE as shown in table.6.For figure (6), the same conclusion can be reached, but the sates for the undershoot values are increased for IAE .

The DE and IWO algorithms are better than PID tuner by MATLAB in transient response specifications, and by all optimal criteria ISE and IAE. Moreover, among these performance indices, the IAE one is more capable than the other in providing minimal overshoot, low rise time and low settling time for the transient response system.

\section{B. Controlling $X B$ for $G_{22 r W B}$}

The same procedures as in 5.1. Assume the input $=0.02$ with lower and upper bounders [-1 -1$]$, [0 0] respectively. The results are depicted in Table. 9 and transient response specifications are shows in Table.10 for ISE, while table.11 and table. 12 for IAE. Fig. 7 and 8 shows step response controlled system for ISE and IAE respectively.

Table.9 The optimal parameters of PI controller for $\mathrm{G}_{22 \mathrm{rWB}}$ using performance index ISE

\begin{tabular}{|c|c|c|c|}
\hline Controller type & $\boldsymbol{K}_{\boldsymbol{P}}$ & $\boldsymbol{K}_{\boldsymbol{i}}$ & $\begin{array}{c}\text { Average No. of } \\
\text { Iteration }\end{array}$ \\
\hline PI-MATLAB & -0.1632 & -.0286 & \\
\hline DE-PI & -0.5009 & -0.471 & 15 \\
\hline IWO-PI & -0.4331 & -0.0465 & 15 \\
\hline
\end{tabular}

Table.10 Transient response parameters of $\mathrm{G}_{22 \mathrm{rWB}}$ for ISE

\begin{tabular}{|c|c|c|c|c|c|}
\hline $\begin{array}{c}\text { Controller } \\
\text { types }\end{array}$ & $\mathrm{Mp} \%$ & $\begin{array}{c}\text { Over } \\
\text { shoot }\end{array}$ & $\operatorname{Ts}$ (minute) & $\operatorname{Tr}$ (minute) & Ess \\
\hline $\begin{array}{c}\text { Without } \\
\text { controller }\end{array}$ & N/A & N/A & N/A & N/A & N/A \\
\hline $\begin{array}{c}\text { PI- } \\
\text { MATLAB }\end{array}$ & 9.4941 & 3.7694 & 26.3414 & 6.0747 & 0 \\
\hline $\begin{array}{c}\text { PI- } \\
\text { DE(ISE) }\end{array}$ & 17.5423 & 5.3579 & 12.4342 & 1.9069 & 0 \\
\hline $\begin{array}{c}\text { PI- } \\
\text { IWO(ISE) }\end{array}$ & 17.3862 & 11.9319 & 11.3989 & 1.7797 & 0 \\
\hline
\end{tabular}

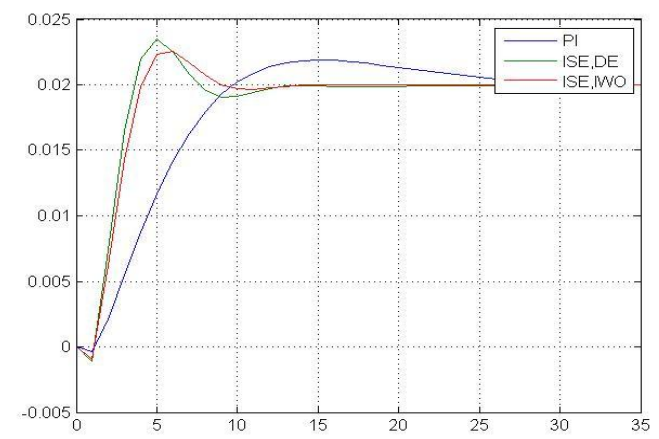

Fig.7. Step Response of PI Controller and PI Controller using DE, IWO for ISE

Table.11 The optimal parameters of PI controller for $\mathrm{G}_{22 \mathrm{rWB}}$ using performance index IAE

\begin{tabular}{|c|c|c|c|}
\hline Controller type & $\boldsymbol{K}_{\boldsymbol{P}}$ & $\boldsymbol{K}_{\boldsymbol{i}}$ & $\begin{array}{c}\text { Average No. of } \\
\text { Iteration }\end{array}$ \\
\hline PI-MATLAB & -0.1632 & -.0286 & \\
\hline DE-PID & -0.2717 & -0.028 & 15 \\
\hline IWO-PID & -0.5101 & -0.0469 & 15 \\
\hline
\end{tabular}

Table.12 Transient response parameters of $\mathrm{G}_{22 \mathrm{rWB}}$ for IAE

\begin{tabular}{|c|c|c|c|c|c|}
\hline Controller types & Mp\% & Over shoot & Ts(minute) & $\operatorname{Tr}(\operatorname{minute})$ & Ess \\
\hline Without controller & N/A & N/A & N/A & N/A & 0.0747 \\
\hline PI-MATLAB & 9.4941 & 3.7694 & 26.3414 & 4.3258 & 0 \\
\hline PI-DE (IAE) & 0 & 6.2333 & 7.7918 & 1.7423 & 0 \\
\hline PI-IWO (IAE) & 17.9261 & 12.1463 & 11.3792 & & 0 \\
\hline
\end{tabular}




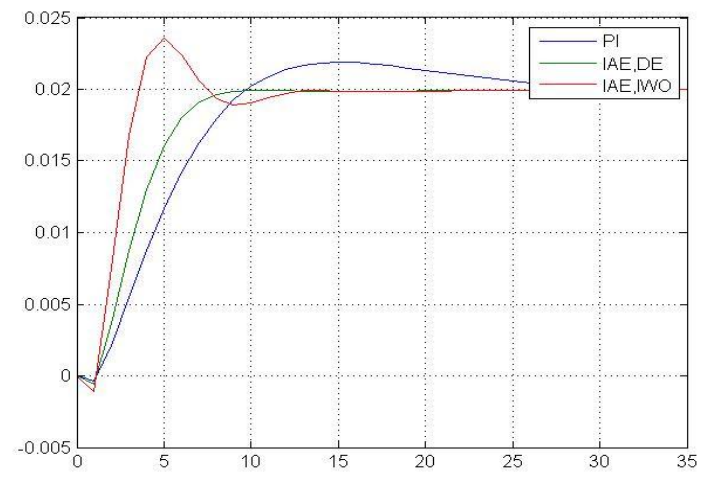

Fig.8. Step Response of PI Controller and PI Controller using DE, IWO for ISE

According to tables (10),(12), The DE and IWO algorithms are better than PID tuner by MATLAB in transient response specifications in produce low rise time and low settling time and as seen in figs(7) and(8) and by all optimal criteria ISE and IAE. Moreover, among these performance indices, the IAE one with DE algorithm is more capable than the other in providing minimal overshoot, low rise time and low settling time for the transient response system but with bigger under shoot than the state with MATLAB-PID tuner.

\section{Conclusions}

In this paper, we have shown how to control a distillation column using optimization algorithms, Interaction between the two loops of distillation column was recommended, so we use simplified decoupling in order to eliminate the interaction between loops and to make the system stable. The decouplers are greatly improved the response of the system. PSO have been employed to optimize a model reduction of the large-scale dimension of distillation process by selecting the best model structures for numerator and denominator transfer function. PI-DE controller showed more advantages than PI-IWO related to transient specifications for controlling top composition (XD) with IAE performance index and PI-DE also showed the same advantages, when compared with PI-IWO for controlling bottom composition (XB),with IAE.This comparison showed clear difference through the curve of the response and the values of the absolute mean square error and the integral square error. There is some undershoot response with starting dynamic for controlling $(\mathrm{XB})$, because the $\mathrm{G}_{22 \mathrm{rWB}}$ system is non-minimum phase (one zero in right hand side of s-plane). Generally Decentralized has the advantages of simplicity (two PID controllers) for binary column and less solution time than the centralized method, which needs four PID controllers and more tuning for each loop. Thus the top and bottom composition of distillation column is controlled and desired performance is achieved.

\section{Acknowledgment}

The authors would like to thank Mustansiriyah University (www.Uomustansiriyah.Edu.Iq) Baghdad - Iraq for its

\section{References}

[1] Gorak Andrzej, Schoenmakers Hartmut. Distillation: Operation and Applications. Academic Press; 2014.

[2] Skogestad Sigurd, Morari Manfred. Understanding the dynamic behavior of distillation columns. Ind. Eng. Chem. Res,vol. 27,no. 10,pp. 1848-1862,1988.

[3] Rein Luus," Time Optimal Control of a Binary Distillation Column”, Dev Chem. Eng. Mineral Process, vol. 1O,no. 1/2, pp. 19$31,2002$.

[4] Morari, M., Lee, J.H.," Model predictive control: past, present and future",Comput. Chem. Eng. Vol. 23,issues 4-5, pp. 667682, May 1999.

[5] Betts John T. "Practical methods for optimal control and estimation using nonlinear programming",. SIAM; 2010.

[6] Luus R. Iterative dynamic programming. Monographs and surveys in pure and applied mathematics. London, UK: Chapman,\& Hall/CRC , 2000.

[7] Osuolale Funmilayo N, Zhang Jie. Energy efficiency optimisation for distillation column using artificial neural network models. Energy. vol.106, pp. 562-578, 2016.

[8] Karacan S, Hapo glu H, Alpbaz M.” Generalized predictive control to a packed distillation column for regulatory problems".Computers \& Chemical Engineering. vol. 22, Supplement 1, pp. S629-S632, 5 March 1998.

[9] Angelica Orjuel, Olga Ramos," PID Control for Distilled Product and Bottom Concentration in a Binary Distillation Column", International Review of Mechanical Engineering (IREME), Vol 11, No 4 ,2017. 
[10] Bisgaard Thomas, Skogestad Sigurd, Abildskov Jens, Huusom Jakob K."Optimal operation and stabilising control of the concentric heat-integrated distillation column (HIDiC)". Computers \& Chemical Engineering. ,vol. 96, pp. 196-211,4 January 2017,.

[11] Fabro João Alberto, Arruda Lucia VR, Neves Flávio. "Startup of a distillation column using intelligent control techniques".Computers \& Chemical Engineering. vol. 30, no. 2, pp.309-320, 2005.

[12] Hori Eduardo Shigueo, Skogestad Sigurd, Al-Arfaj Muhammad A.” Self-optimizing control configurations for two-product distillation columns". In: :590Institution of Chemical Engineers; 1999; pp. 590-599,2006.

[13] Akemi G'alvez and Andr'es Iglesias," Binary Distillation Column Design Using Mathematica", Computational Science ICCS, vol. 2657,pp.848-857,2003.

[14] Jiann-Shiou Yang," Optimization-Based PI/PID Control for a Binary Distillation Column”, 2005 American Control Conference June , pp. 3650 - 3655 ,2005.

[15] M.Sharmila , V.Mangaiyarkarasi," Modeling and Control of Binary Distillation Column”, International Journal of Advanced Research in Electrical, Electronics and Instrumentation Engineering, Vol. 3, Special Issue 4, May 2014.

[16] Wood RK and Berry MW. "Terminal composition control of binary distillation column". Chem Eng Sci,vol. 28,no. 9, pp. 1707-1717, 1973.

[17] Luyben, W.L.," Distillation decoupling”.,AIChE Journal,vol.16,no. 2,pp. 198-203,1970.

[18] Wang, Q. G., Huang, B., and Guo, X. ,"Auto-tuning of TITO decoupling controllers from step tests", ISA Trans. 2000, vol.39,no.4, pp.407-418,2000.

[19] Lu Liu, Siyuan Tian, Dingyu Xue,et al.” A Review of Industrial MIMO Decoupling Control”, International Journal of Control, Automation and Systems vol.17,pp 1-9, 2019.

[20] Luyben,W.L.," Distillation decoupling”.,AIChE Journal,vol.16,no. 2,pp. 198-203,1970.

[21] G.J. Silva, A. Datta, S.P. Bhattacharyya," Controller design via Pade approximation can lead to instability", Proceedings of the 40th IEEE Conference on Decision and Control ,IEEE, pp. 4733-4737 ,2002.

[22] Russell C. Eberhart,Yuhui Shi," Comparison between Genetic Algorithms and Particle Swarm Optimization", Conference: Evolutionary Programming VII, 7th International Conference, EP98, San Diego, CA, pp. 611-616,1989

[23] Sidhartha Panda,N. P. Patidar," Evolutionary Techniques for Model Order Reduction of Large Scale Linear Systems", International Journal of Applied Science, Engineering and Technology ,vol.5,No.1, 2009.

[24] Qibing Jin, QiWang and Liye Liu," Design of decentralized proportional-integral-derivative controller based on decoupler matrix for two-input/twooutput process with active disturbance rejection structure", Advances in Mechanical Engineering,vol.8,No.6,2016.

[25] Saša Lj. Prodanovi, Novak N. Nedi,et al.," Modified approach to distillation column control”, Hem. ind. ,vol. 71, no. 3,pp. 183-193, 2017.

[26] Trias Andromeda, Azli Yahya, Syahrullail Samion," Differential Evolution for optimization of PID gain in electrical discharge control system", Transactions of the Canadian Society for Mechanical Engineering, Vol. 37, No. 3, 2013.

[27] Mehrabian, A. R., \& Lucas, C. (2006).” A novel numerical optimization algorithm inspired from weed colonization". Ecological Informatics, vol. 1,no.4,pp. 355-366,2016.

[28] MojganMisaghi,MahdiYaghoobi,'Improved invasive weed optimization algorithm (IWO) based on chaos theory for optimal design of PID controller", Journal of Computational Design and Engineering Vol. 6, Issue 3, pp. 284-295, July 2019.

\section{Authors' Profiles}

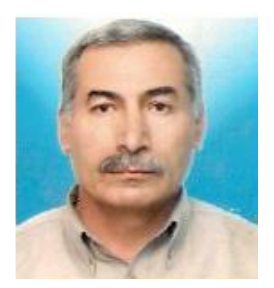

Nasir Ahmad Al-Awad he received B.Sc. degree in control and system engineering from Technological University, Iraq, in 1981, M.Sc. degree in control and instrumentation engineering from Technological University, Iraq, in 1984, He is currently Prof. at Al-Mustansiriyah University, Baghdad, Iraq. His research interests include control theory, computer control and computer aided design of control system, e-mail: nasir.awad@uomustansiriyah.edu.iq

Afaf Jebar Muter is a M.Sc. Student at Computer Engineering Department, AL-Mustansiriyah University, 2019. B.Sc. Degree from Computer Engineering Department, Almustansiriyah university, Iraq, in,2017. E-mail: afak.jeber@gmail.com.

How to cite this paper: Nasir Ahmed Alawad, Afaf Jebar Muter, "Optimal Control of Model Reduction Binary Distillation Column", International Journal of Modern Education and Computer Science(IJMECS), Vol.13, No.1, pp. 59-68, 2021.DOI: 10.5815/ijmecs.2021.01.05 